\title{
The influence of temperature variation in the prediction of the pavement overlay life
}

\author{
Manuel J. C. Minhoto* -- Jorge C. Pais** -- Paulo A. A. Pereira** \\ -- Luís G. Picado-Santos***
}

\author{
*Instituto Politécnico de Bragança-Escola Superior de Tecnologia e de Gestão \\ Campus de Santa Apolónia, Apartado 134, 5301 -857 Bragança \\ minhoto@ipb.pt \\ ** University of Minho \\ Department of Civil Engineering, Campus Azurém, 4800-058 Guimarães, Portugal \\ jpais@civil.uminho.pt \\ ppereira@civil.uminho.pt \\ *** University of Coimbra \\ Department of Civil Engineering, Coimbra, Portugal \\ picsan@dec.uc.pt
}

\begin{abstract}
This paper describes a study of the influence of temperature variation in the pavement overlay life, using finite-element methodology to consider the most predominant type of overlay distress observed in the field: reflective cracking. The temperature variation has a significant influence on thermally induced stresses that, in turn, affects the overlay predictive service life. This paper presents a three-dimensional (3D) finite element analysis to predict the pavement overlay life considering a combination of thermal pavement conditions with traffic loads in a pavement overlay modelled on a cracked pavement.

The results present the influence of temperature variation in the cracked layer and overlay, as function of the initial pavement temperature. Furthermore, a comparison between the overlay life due to traffic loading and temperature variation in the overlay life is also presented. Finally, the overlay life was predicted using asphalt rubber and conventional mix fatigue laws allowing to conclude that asphalt rubber mixes exhibit more pavement life compared to conventional mixes even when the effects of temperature (temperature variation) are considered in the overlay design.
\end{abstract}




\section{Introduction}

Bituminous overlays have been the most used method in pavement rehabilitation. The service life of an overlay depends on its performance in different distress modes. In an overlay, cracks will develop and propagate to the pavement surface, directly above pre-existing cracks, under static and repetitive loading, during the first few years of service. This mode of distress is traditionally referred to as "reflective cracking" and constitutes one of the major concerns of road organisms in the whole world. Several authors [SOU 2002] [BON, 2000] suggest that different mechanisms responsible fr the origin and propagation of cracks in pavement overlays can be identified [SOU 2002]:

1. Thermal stresses from thermal fatigue occur when temperature variations induce cyclic openings and closures of cracks in the old pavement which, in turn, induce stre ss concentrations in the overlay.

2. Thermal stresses as a result of a rapid cooling down of the top layer induce critical tensile stresses in the overlay.

3. Repetitive traffic loads induce additional distress in the overlay and increase the rate of crack propagation;

4. Soil movements - settlements (downwards), frost heave (upwards) and shrinkage of clays (horizontal nature).

In regions that experience large daily temperature variations or extremely low temperatures, thermal conditions play a major role in the reflective cracking response of a multilayered pavement structure. Binder properties (stiffness, aging, penetration, etc...) are sensitive to temperature variations. Furthermore, the accumulated restrained thermal stresses as a result of a decrease in temperature will accelerate the reflective cracking phenomenon.

The combination of the two most important factors, (1) loads passing above (or near) the crack and (2) the overlay under tension due to a temperature decrease, have been identified as the most likely causes of high states of stress and strain above the crack and responsible for reflective cracking [SHA 1990].

To delay, or minimize, crack propagation in overlays, several options are available to extend the life of a conventional overlay. One of them is the use of thicker overlays or the optimization of the stiffness and strength of the overlay mixture by adding fibers or applying modified bitumen. Stress-relieving systems can also be added for reinforcements. Bitumen modification is used to improve the reflective cracking overlay life in thermal and traffic combinations by using an Asphalt Rubber (AR) hot mix. Asphalt rubber (the wet process), has been shown to reduce reflective cracking and improve resistance to thermal changes.

Possible benefits of adding Crumb Rubber Modifier (CRM) to Hot Mix Asphalt (HMA), using the wet process, exist in both the high and low temperature ranges. The use of asphalt rubber binder in HMA, results in a reduction of the binder temperature susceptibility and an increase in the binder film thickness of the aggregates [EPP, 2000]. 
These modified binder properties are believed to improve the performance of thermal reflective cracking. A mixture with CRM binder is more resistant to thermal changes than conventional mixtures due to a reduction in stiffness at low temperatures. Enhanced elastic properties of the modified binder improve the mixtures ability to withstand tensile stresses caused by reflective cracking from temperature variations. The CRM binder also allows the use of a softer grade of asphalt cement to gain flexibility at low temperatures without loss of rutting resistance at high temperatures [EPP, 2000].

This study evaluates the importance of temperature variation in overlay life. It involves the calculation of stresses and strains generated by two cases of loading: $130 \mathrm{kN}$ heavy axle loading and thermal loading (rapid cooling rate). Such stresses and strains are concentrated above the existing cracks, creating an active zone of overlay failure or crack propagation. Furthermore, the state of stresses and strains were calculated for conventional dense-graded HMA and Asphalt Rubber HMA gap-graded overlay.

\section{Background}

Sousa et al [SOU 2002] concluded that when reflective cracking is caused by traffic loads, complex patterns of distresses have been recorded. In these cases, a combination of Modes I and II crack openings are simultaneously present. Differential vertical movements ( $\Delta$-vertical) in existing cracks have been known to be a major cause of reflective cracking in overlays [HAL 1989] [HAL 1990]. However, for thermal induced cracks, only Mode I is considered to be the main mode of cracking.

Daily temperature variations have an important influence in the pavement thermal state a few decimetres below the surface. The time variation of pavement stresses is controlled by climatic conditions and thermal diffusivity of materials [BON, 2000]. Depending on the level of temperature variation, stress is induced in the overlay in two different ways: through restrained shrinkage of the overlay and through the movements of existing cracked layers.

First of all, restrained shrinkage of the overlay itself causes transverse and longitudinal tensile stresses. These stresses are dependent on: overlay mix stiffness, thermal coefficient of contraction, Poisson ratio and pavement thermal gradient. Given the fact that bitumen aging takes place at the surface, the phenomena described above induces the crack to initiate and propagate from the pavement surface downward. This phenomenon occurs not only in overlays, but also in new pavement structures. In that case, the use of softer asphalts, like asphalt rubber (or SBS-polymer modified bitumen), presents a good option in delaying reflective cracking in overlays.

Secondly, the movements of the existing slabs exert a repeated splitting at the bottom of the overlay inducing important stresses in the overlay. The thermal movements of a cracked layer resulting from thermal shrinkage are dependent on 
overlay mix stiffness, cracked layer mix stiffness, cracked layer mix thermal coefficient of contraction, overlay thickness, degree of friction between the overlay and distance between cracks.

Sousa et al [SOU 2002] proposed a mechanistic-empirical methodology which simultaneously imposes Modes I and II deflection patterns on asphalt concrete specimens into a coherent procedure. The influence of pavement characteristics on the state of stress and strain was considered by defining a deviator strain such as the Von Mises stress. This strain, called the "Vo n Mises strain", was calculated through the expression [1].

$$
\varepsilon_{V M}=\sqrt{\frac{1}{2}\left(\left(\varepsilon_{1}-\varepsilon_{2}\right)^{2}+\left(\varepsilon_{1}-\varepsilon_{3}\right)^{2}+\left(\varepsilon_{2}-\varepsilon_{3}\right)^{2}\right)}
$$

Where:

$$
\begin{aligned}
& \varepsilon_{V M}=\text { "Von Mises strain" } \\
& \varepsilon_{1}, \varepsilon_{2}, \varepsilon_{3}=\text { Principal strains }
\end{aligned}
$$

This mechanistic-empirical methodology is based on results fromflexural fatigue tests, in a controlled strain, and the Von Mises deviator strain is used as the "controller" parameter of the phenomenon. For beam fatigue test conditions subjected to four-point bending, $\varepsilon_{V M}$ can also be written as:

$$
\varepsilon_{V M}=\varepsilon_{1}(1+v)
$$

This parameter can be used to obtain the reflective cracking fatigue life. The fatigue behavior of a bituminous mixture can be expressed as a relationship between the number of cycles to failure and one of the following variables: tensile strain, tensile stress, Von Mises stress, "Von Mises strain", strain energy of distortion or total energy of strain.

In accordance with the procedure presented in Figure 5, this study calculates the stresses and strains in the overlay zone above existing cracks through a $3 \mathrm{D}$ finite element analysis, for traffic load, thermal load and the combination of both load cases. With these strains, the average Von Mises strains, $\varepsilon_{\mathrm{VM}}$, are calculated considering the active zone of the overlay located above the simulated crack. Equation [2] relates the Von Mises strain with fatigue strain and is used to evaluate the pavement life for combined existing thermal stresses and traffic load stresses. The evaluation of thermal fatigue effects on the predictive overlay life does not fit in the scope of this study.

\section{Pavement modelling}

The Finite-Element methodology was adopted to model the pavement behavior. This approach was selected because it appeared to be the most sensible way to 
address the unusual stresses and strains generated from heavy traffic and thermal load combination. Traditionally, pavement structures are idealized as a set of horizontal layers of constant thickness, homogeneous, continuous and infinite in the horizontal direction, resting on subgrade, semi-infinite in the vertical direction. In the crack reflection study, the top layer represents the bituminous overlay and the subjacent layer represents the cracked layer. The developed structural model configuration of pavement was based on the previous principles and is presented in Figure 1.

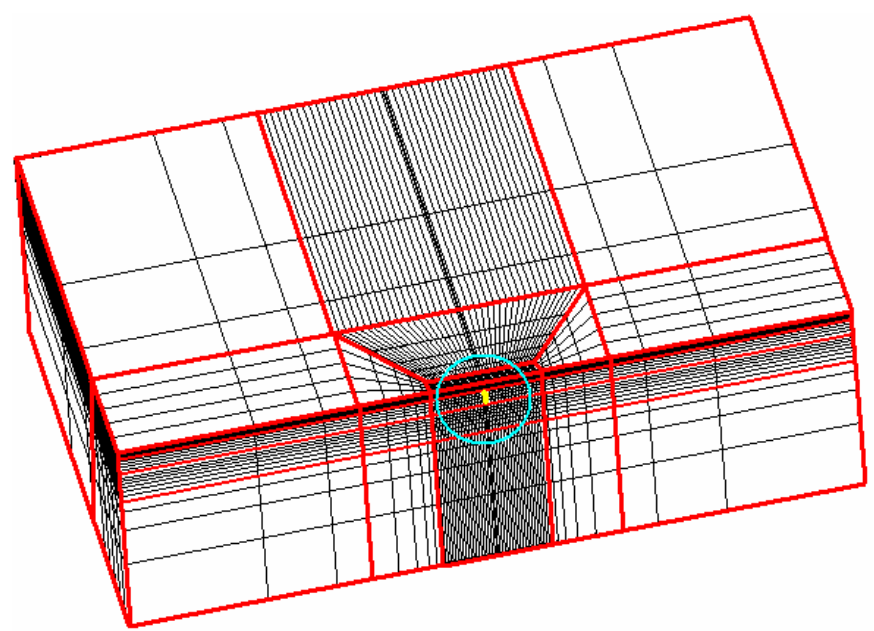

Figure 1. 3D Representation of Finite Element Mesh

\subsection{Finite Element Analysis}

The finite element model used in numerical analysis was performed using a general Finite Elements Analysis source code, ANSYS 5.6. In this model, the principle of the linear elasticity was adopted in order to represent the material behavior. When designing the finite-element mesh to model the mechanical analysis, the following factors were considered:

- a finer element size was adopted closer to the pavement surface and the wheel load zone, where stress gradients are highest,

- a finer element size was adopted in the overlay zone above the crack;

- due to the s ymmetry, only half of the pavement was modeled;

- the convergence of results between the FE model and existing models of vertical and horizontal crack activity, Von Mises strains, fatigue strains and rutting strains, were verified;

The 3D mesh model used for the analysis of the traffic load and thermal load is given in Figure 1, Figure 2 and Figure 3. In both loading cases, the number of elements was 16330. For three-dimensional analysis, 3-D twenty-node structural solid element, SOLID186, was used. This element assumes quadratic approximation of the field displacements and allows three degrees of freedom per node, as is shown in Figure 4. 


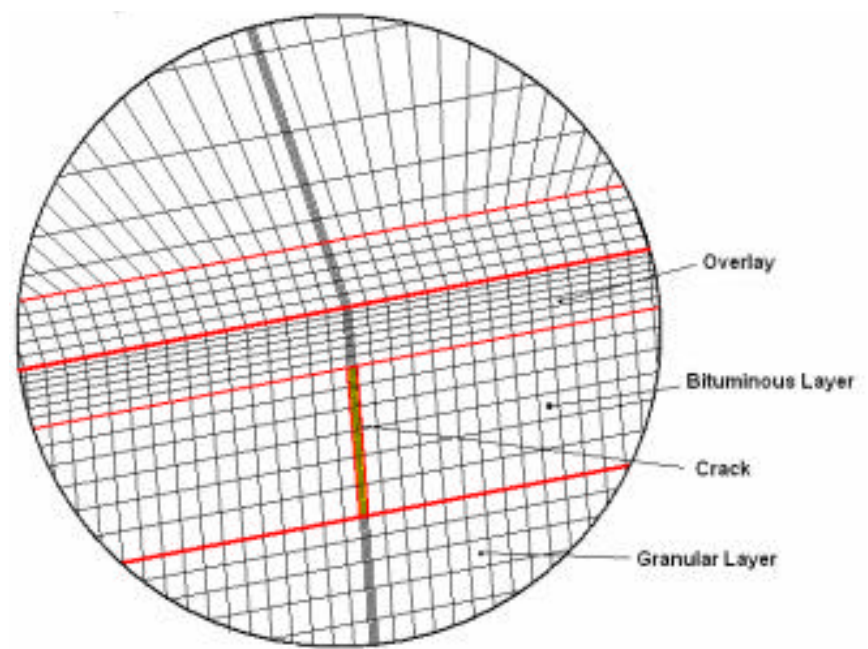

Figure 2. Crack location

The analyzed pavement has a length of $7.45 \mathrm{~m}$, a width of $4.5 \mathrm{~m}$ and a variable thickness. The crack was modeled in all thickness of the cracked layer and the width was set to $0.010 \mathrm{~m}$ Only longitudinal cracks were simulated. The evaluation of the effect of crack width in the overlay life does not fit in the scope of this study, having been adopted, by default, the proposed value that makes possible a maximum activity of the crack and that prevents the possibility of friction between the edges of the crack.

To proceed with this analysis, it was necessary to establish the following assumptions:

- The volume changes resulting from the freezing and thawing of moisture were not considered;

- All pavement layers were homogeneous, elastic and isotropic;

- Full bond was applied between all pavement layers.

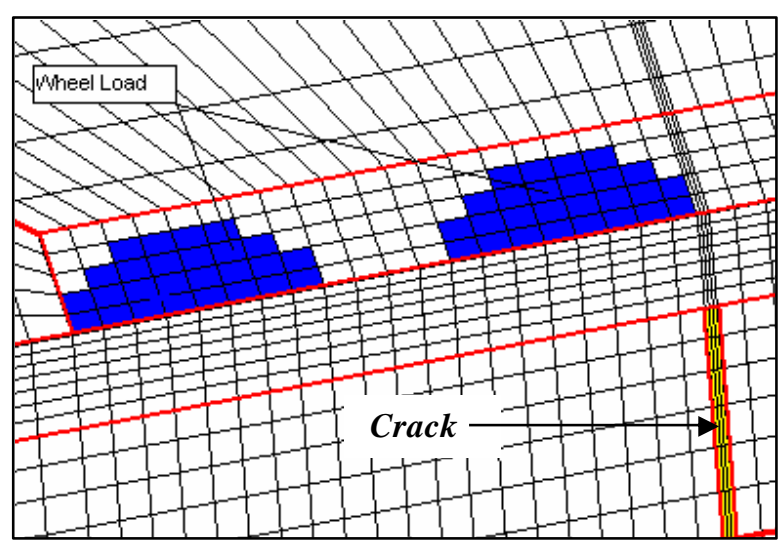

Figure 3. Wheel load configuration 


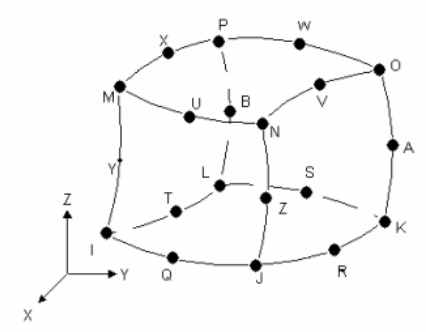

Figure 4. 3-D twenty-node structural solid element

The lateral and inferior boundaries of the pavement are composed of simple supports in each node, oriented in the perpendicular direction to the boundary surfaces. The verification and calibration of the FEM mechanical model of cracked pavement was accomplished by comparing the calculated vertical crack movements and Von Mises deviator strain to the values obtained from calibrated statistical expressions developed by Sousa et al [SOU 2002], resulting in a good convergence.

\subsection{Material mechanical properties}

In this analysis, it was assumed that the pavement materials have a linear elastic behavior and that they are isotropic and homogeneous. The stiffness of the bituminous layers was considered to be dependent of the temperature. For the purposes of this paper, it is reasonable to use an elastic analysis because it is unnecessary to calculate the state of stress and strain in the crack tip. The state of stress and strain might only be calculated in the zone above the crack. In the next stage of this research, the nonlinear behaviour of the overlay will be considered.

The temperature influence in the mixture stiffness was estimated by using binder data and Shell models based on the binder stiffness and volumetric characteristics of the mixture. The binder stiffness, determined from the Van Der Poel monograph, is dependent on temperature, penetration index and loading time. A loading frequency of $10 \mathrm{~Hz}$ was adopted. To take into account the thermal contraction, the estimated mixture stiffness was calculated for a loading time of 10 seconds, as proposed by [EPP 2000].

In this analysis, a constant coefficient of thermal contraction was assumed, independent of the temperature. For the evaluation of thermal loading effect, the following values were adopted: $\alpha=1.4 \times 10^{-5}$ for conventional mix and $\alpha=2.16 \times 10^{-5}$ for Asphalt Rubber mix. The Poisson ratio was assumed as a constant value and the following values were considered:

- $\quad ?=0.35$ for bituminous layers;

- $\quad ?=0.3$ for granular layers;

- $\quad ?=0.35$ for subgrade.

The adopted thickness and stiffness for all layers is presented in Table 1. The ageing effect is simulated by affecting the bituminous parameters through adequate factors. 
Table 1 - Study cases conditions

\begin{tabular}{|c|c|c|c|c|c|}
\cline { 2 - 6 } \multicolumn{1}{c|}{} & \multicolumn{3}{c|}{ Thickness (m) } & \multicolumn{2}{c|}{ Stiffness (MPa) } \\
\hline $\begin{array}{c}\text { Structure } \\
\text { Type }\end{array}$ & Overlay & $\begin{array}{c}\text { Cracked } \\
\text { layer }\end{array}$ & $\begin{array}{c}\text { Granular } \\
\text { Layer }\end{array}$ & $\begin{array}{c}\text { Granular } \\
\text { Layer }\end{array}$ & Subgrade \\
\hline PAV01 & 0.02 & 0.10 & 0.30 & 250 & 100 \\
\hline PAV02 & 0.07 & 0.15 & 0.30 & 250 & 100 \\
\hline PAV03 & 0.10 & 0.25 & 0.30 & 250 & 100 \\
\hline
\end{tabular}

\subsection{Loads}

The loading configuration is presented in Figure 3 and is defined as a surface load (pressure) near the vertical location of the crack, simulating the $130 \mathrm{kN}$ standard axle load.

The thermal loading was characterized as a combination of two parameters: initial uniform temperature in the bituminous layers, $\mathrm{Ti}$, and a temperature variation, $\Delta \mathrm{T}_{\mathrm{i}}$, as result of a rapid cooling down in the overlay and cracked layer. In this study, the adopted values for the initial uniform temperature were: $20^{\circ} \mathrm{C}, 10^{\circ} \mathrm{C}$ and $0^{\circ} \mathrm{C}$. The adopted values for $\Delta \mathrm{T}_{\mathrm{i}}$ were: $-5^{\circ} \mathrm{C},-15^{\circ} \mathrm{C}$ and $-30^{\circ} \mathrm{C}$. Although the temperature variation of $-30^{\circ} \mathrm{C}$ in a cracked layer is unusual, this represents an extreme situation of crack opening which may be analyzed. Thus, the thermal loading is defined as a set of temperatures in the mechanical model affected by temperature variation. The origin of these sets of temperatures does not fit in the scope of this study.

\subsection{FEM Analysis Procedure}

A 3D linear elastic model, based on the ANSYS 5.6 software, was used to calculate the shear strains above the crack zone and to predict the overlay life caused by the effect of temperature variation and traffic loading. The analysis procedure is schematized in Figure 5 and involved multiple 3-D finite-element runs.

To evaluate the temperature influence in the overlay life, three pavements were analyzed (characteristics are presented in Table 1). For each pavement, one of the 3 temperatures $\left(20^{\circ} \mathrm{C}, 10^{\circ} \mathrm{C}\right.$ and $\left.0^{\circ} \mathrm{C}\right)$ was selected as the initial (or reference) temperature. For each of these temperatures, variations $\left(5^{\circ} \mathrm{C}, 15^{\circ} \mathrm{C}\right.$ and $\left.30^{\circ} \mathrm{C}\right)$ we re applied, separately, to the cracked layer and overlay, resulting in 144 combinations.

For each numerical processing, the crack width was maintained constant and the crack depth was defined equal to the thickness of the cracked layer. Crack width variations occur only as a result of cracked layer temperature variation. Each numerical processing represents a mechanical analysis that computes the stress and strain components for the nodes above the crack.

Results obtained from traffic loading and thermal loading were added and the Von Mises strain above the crack zone (Figure 6) was calculated. This Von Mises strain was used to estimate the overlay life. Equation [2] was used to relate the Von 
Mises strain to the fatigue strain concept used in flexural fatigue laws which are used to evaluate the life prediction of conventional pavements.

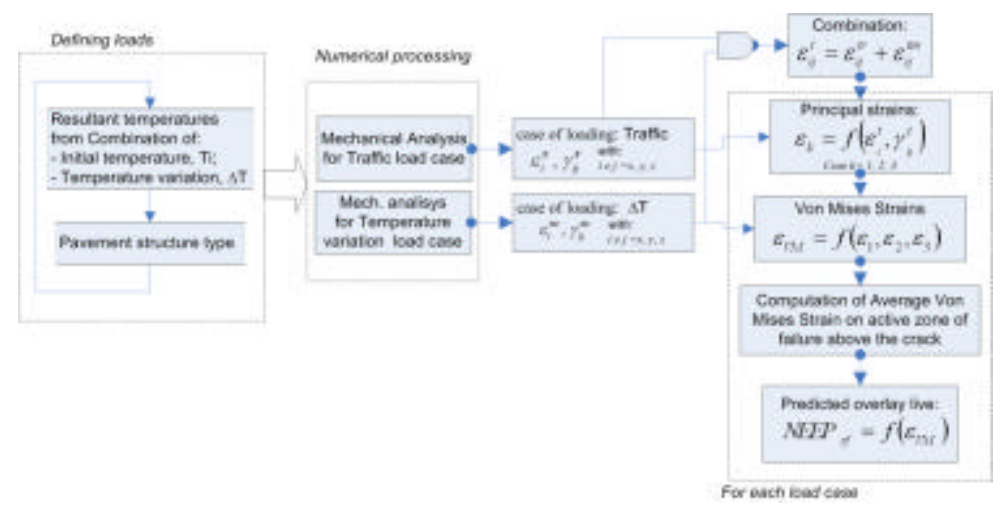

Figure 5. Calculation of the predictive overlay life procedure

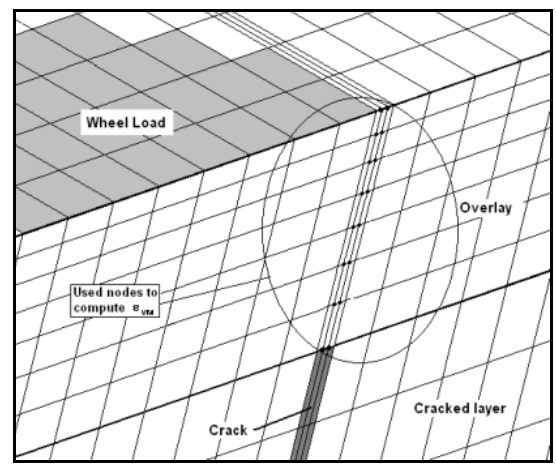

Figure 6. Used nodes to compute the Von Mises strains above the crack zone

\section{Finite Elements results}

This work is part of a research in which the temperature phenomenon will be considered in the overlays design. The analysis made in this study was carried out to observe the following aspects :

- Influence of traffic and temperature variation in the overlay life;

- Influence of temperature variation in the overlay life;

- Influence of uniform temperature variation in bituminous layers in the overlay life.

\subsection{Influence of Traffic and Temperature Variation in the Overlay Life}

The first study performed in this project was the influence of traffic and temperature loading in the overlay life for all pavements and for all combinations of 
temperature variations on both overlay and cracked layers. The results presented in Figure 7, 8 and 9 show this influence. In these figures, "DTbet" represents the temperature variation in the cracked layer, " $\Delta \mathrm{Tovl}$ " represents the temperature variation in the overlay, "PAVXX" represents the pavement $\mathrm{XX}$ and "Tinic" represents the initial temperature.

The first analysis made was the study of the influence of traffic load action on overlay life, taking into account that temperature variation only affects the stiffness of bituminous layers. Thus, as the temperature decreases, the stiffness of bituminous layers increases and the state of strain in the overlay decreases. As a result, the overlay life increases.

The influence of temperature variation on state of stress was also made and it was concluded that as the temperature decreases, the overlay life also decreases. Although this conclusion is evident in all cases studied, some increases of the overlay life occur when the effect of the traffic loading is greater than the effect of the temperature variation. However, this was evident only where there were small temperature variations.

Some differences in the pavement behavior verified in this analysis were reported for all types of pavements studied. These differences are attributed to the bearing capacity of the different pavements analyzed. For thick pavements, the temperature variation is more important than the effect of traffic. In thin pavements, traffic can be pointed as the main factor affecting the overlay life.

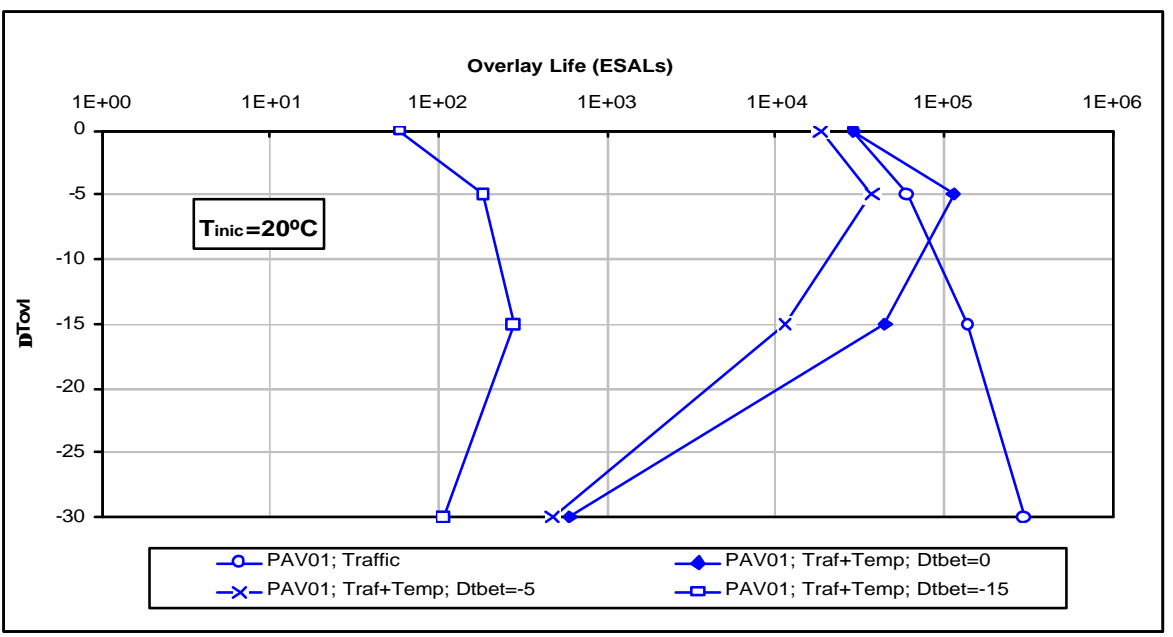

Figure 7. Overlay life of PAVO1 as function of $\Delta$ Tovl, for traffic loading only and for traffic loading + temperature loading - Tinitial $=20^{\circ} \mathrm{C}$ 


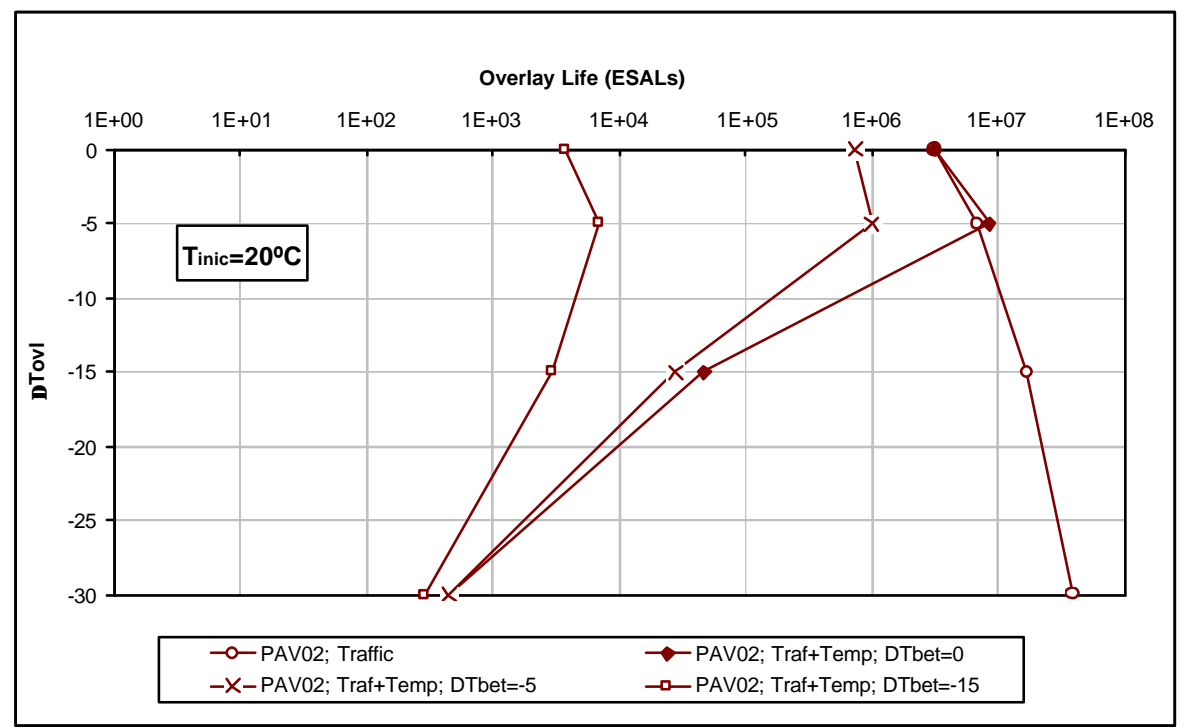

Figure 8. Overlay life of PAV02 as function of $\Delta$ Tovl, for traffic loading only and for traffic loading + temperature loading - Tinitial $=20^{\circ} \mathrm{C}$

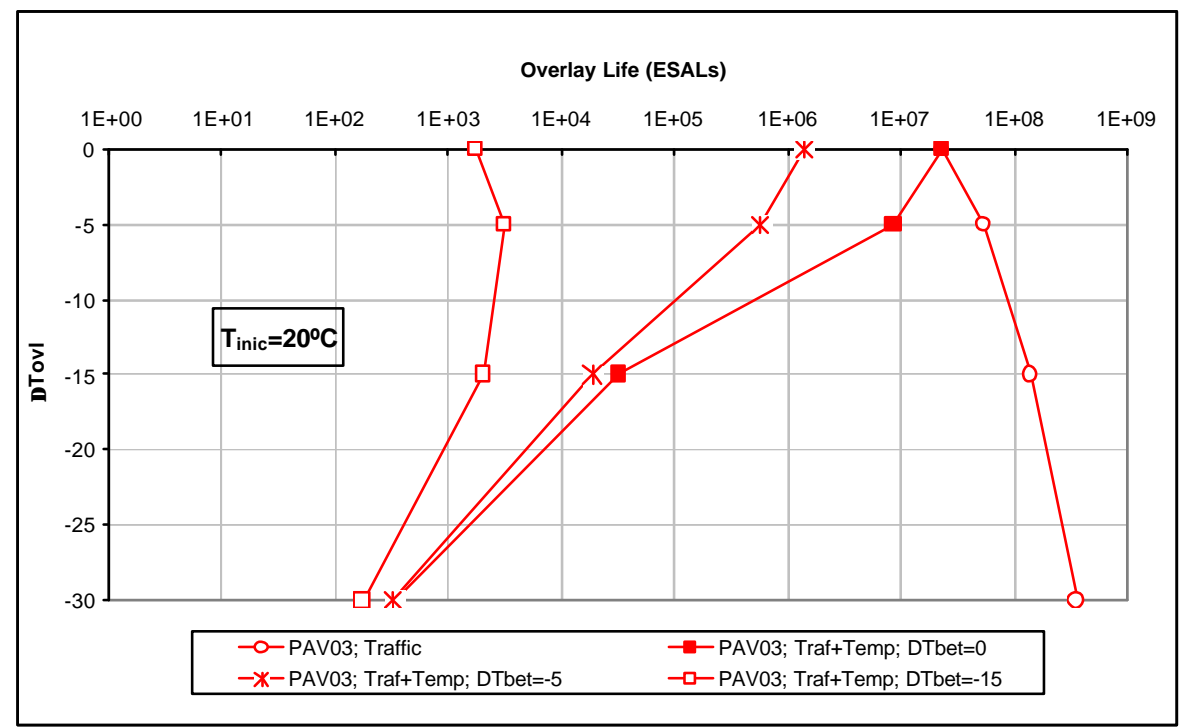

Figure 9. Overlay life of PAV03 as function as $\Delta$ Tovl, for traffic loading only and for traffic loading + temperature loading - Tinitial $=20^{\circ} \mathrm{C}$ 


\subsection{Influence of Temperature Variation in the Overlay Life}

The results presented in Figure 10, 11 and 12, for the initial temperature of $20^{\circ} \mathrm{C}$, represent the influence of temperature variation in the overlay life for each pavement studied. The vertical lines (Design life - PAV01, PAV02 and PAV03) represent the pavement life design with no change in the temperature of bituminous layers (designed only for the initial temperature of $20^{\circ} \mathrm{C}$ ). The results conclude that the overlay life decreases when the temperature in the bituminous layer decreases.

For small temperature variations, the overlay life increases whenever the reduction of this life, due to temperature variation, is less than the increase of the overlay life due to traffic loads. These conclusions are valid for both pavements studied. However, the temperature influence is more evident in stiff pavements as observed for PAV03 pavement. These conclusions can also be applied to the other initial pavement temperatures $\left(10\right.$ and $\left.0^{\circ} \mathrm{C}\right)$ (Figures $13,14,15$ and 16).

The influence of the initial temperature in the overlay life for PAV03 is presented in Figure 17 and 18. Thus, it can be concluded that when the initial temperature increases, the overlay life also increases. The same conclusion was also found for increases in the cracked layer temperatures.

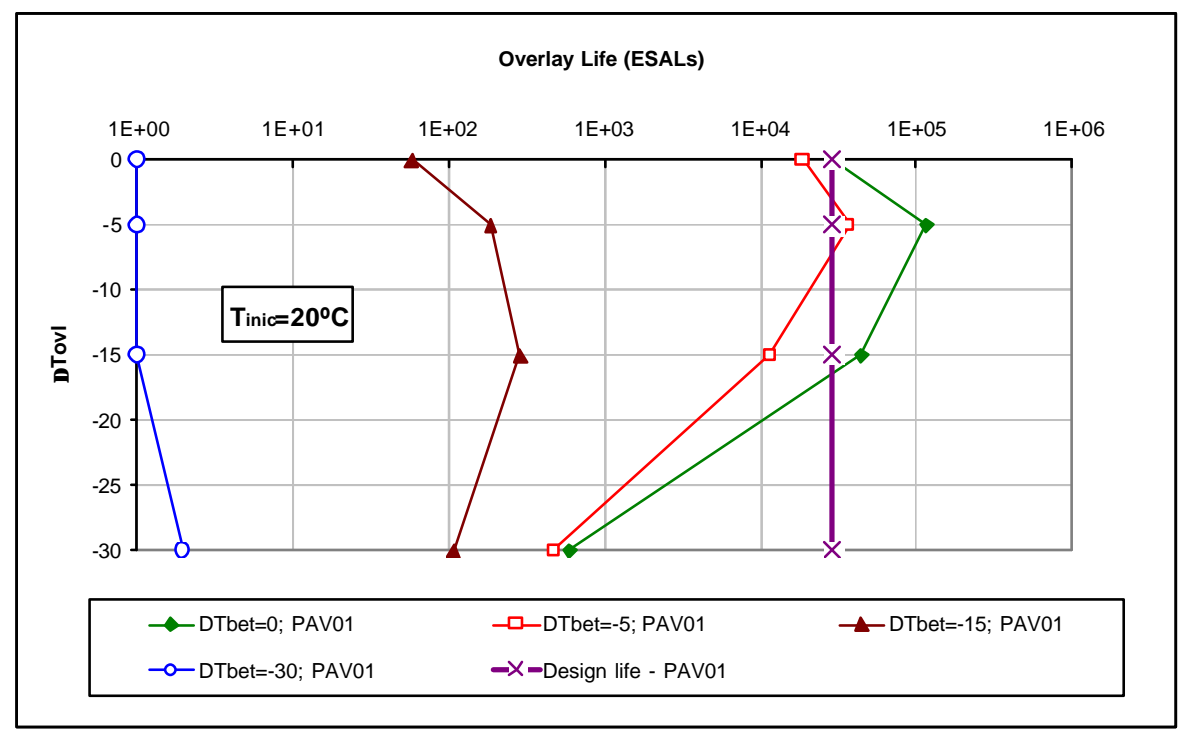

Figure 10. Overlay life of PAVO1 as function of $\Delta T$ Tovl, for initial temperature of $20^{\circ} \mathrm{C}$ 


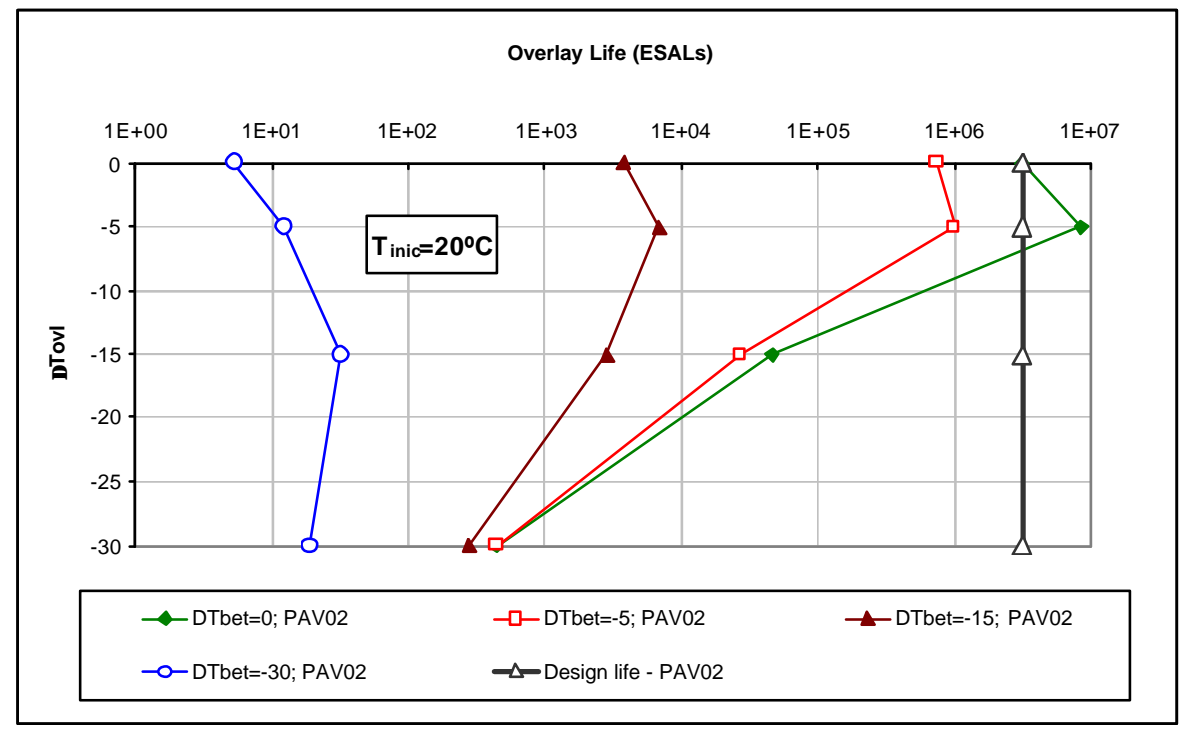

Figure 11. Overlay life of PAVO2 as function of $\Delta T$ Tovl, for initial temperature of $20^{\circ} \mathrm{C}$

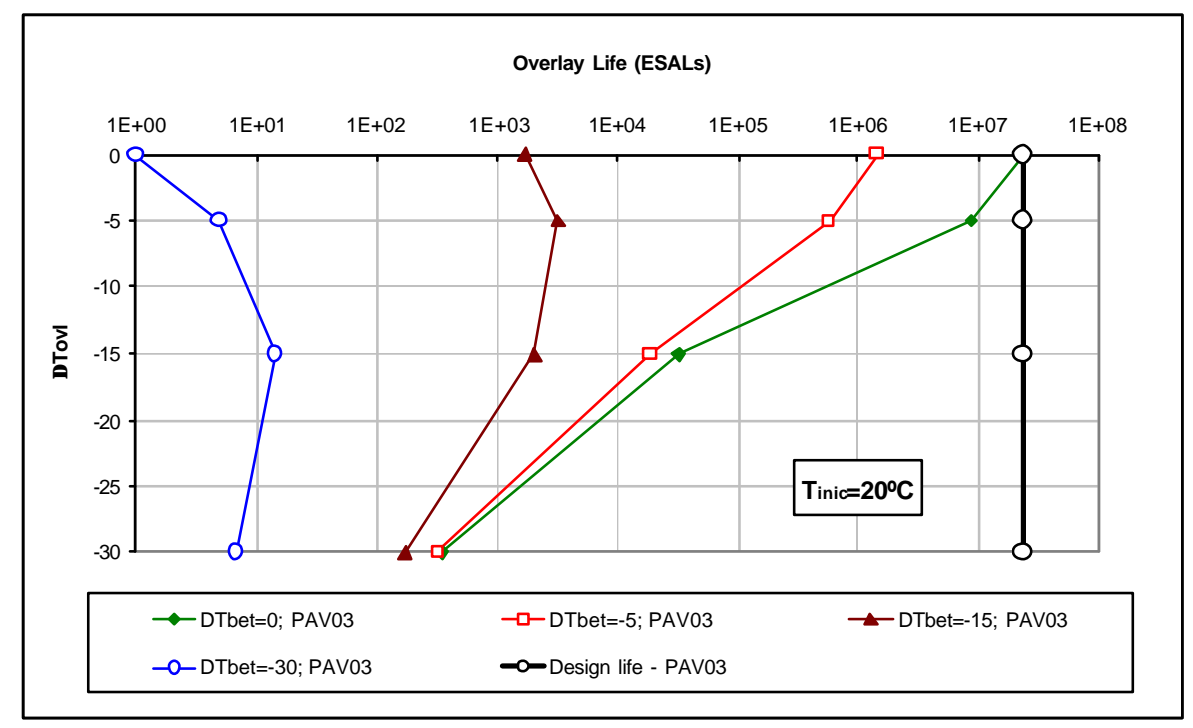

Figure 12. Overlay life of PAV03 as function of $\Delta T$ Tovl, for initial temperature of $20^{\circ} \mathrm{C}$ 


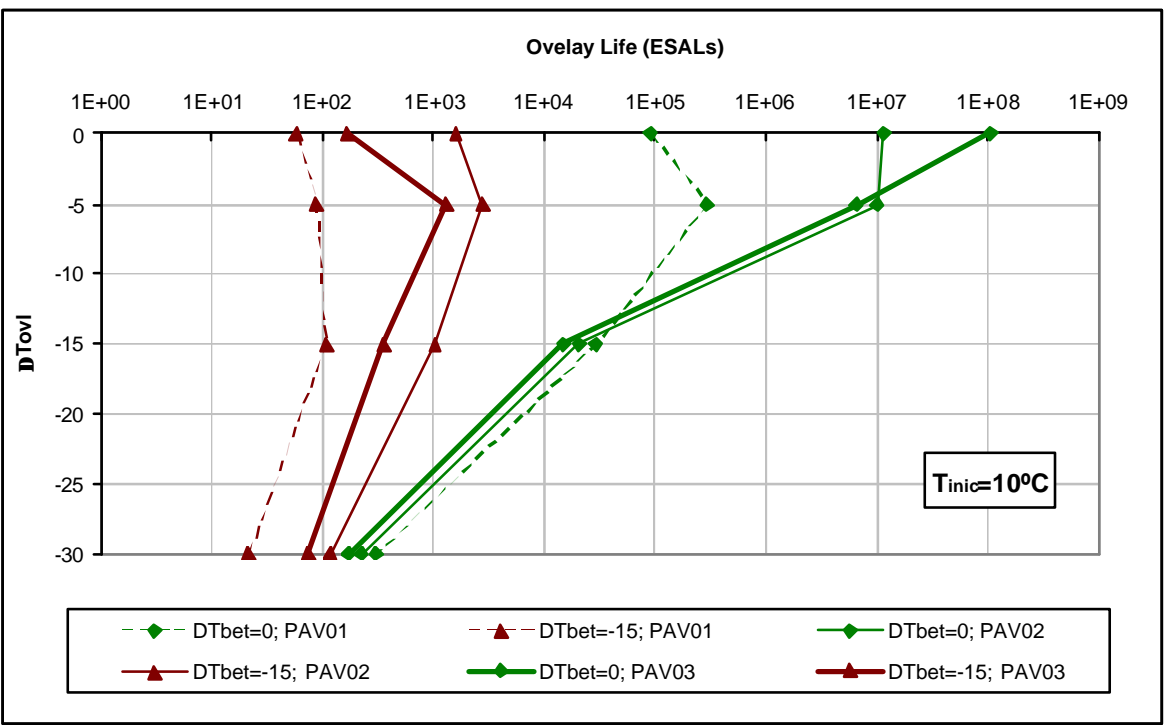

Figure 13. Overlay life of PAV01, PAV02 and PAV03, as function of $\triangle T$ Tovl, for initial temperature of $10^{\circ} \mathrm{C}$ and for $0^{\circ} \mathrm{C}$ and $-15^{\circ} \mathrm{C}$ cracked layer temperature variation (Tbet)

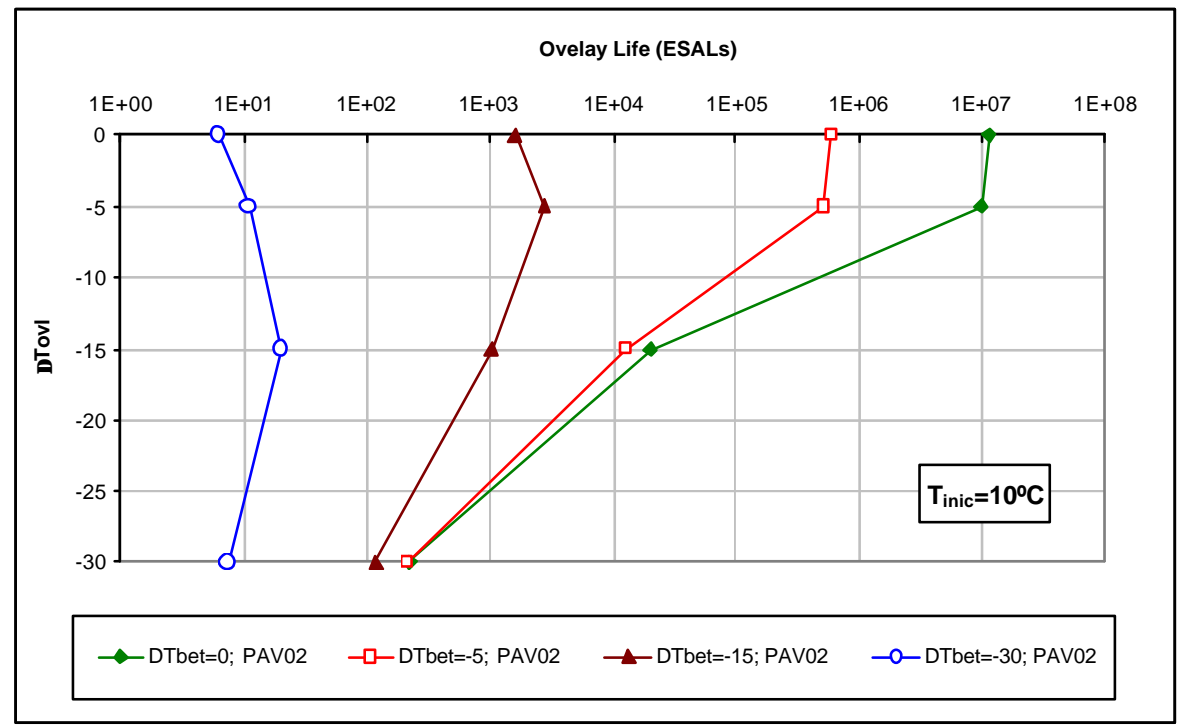

Figure 14. Overlay life of PAVO2 as function of $\Delta$ Tovl, for initial temperature of $10^{\circ} \mathrm{C}$ and $0^{\circ} \mathrm{C},-5^{\circ} \mathrm{C},-15^{\circ} \mathrm{C}$ and $-30^{\circ} \mathrm{C}$ cracked layer temperature variation (Tbet) 


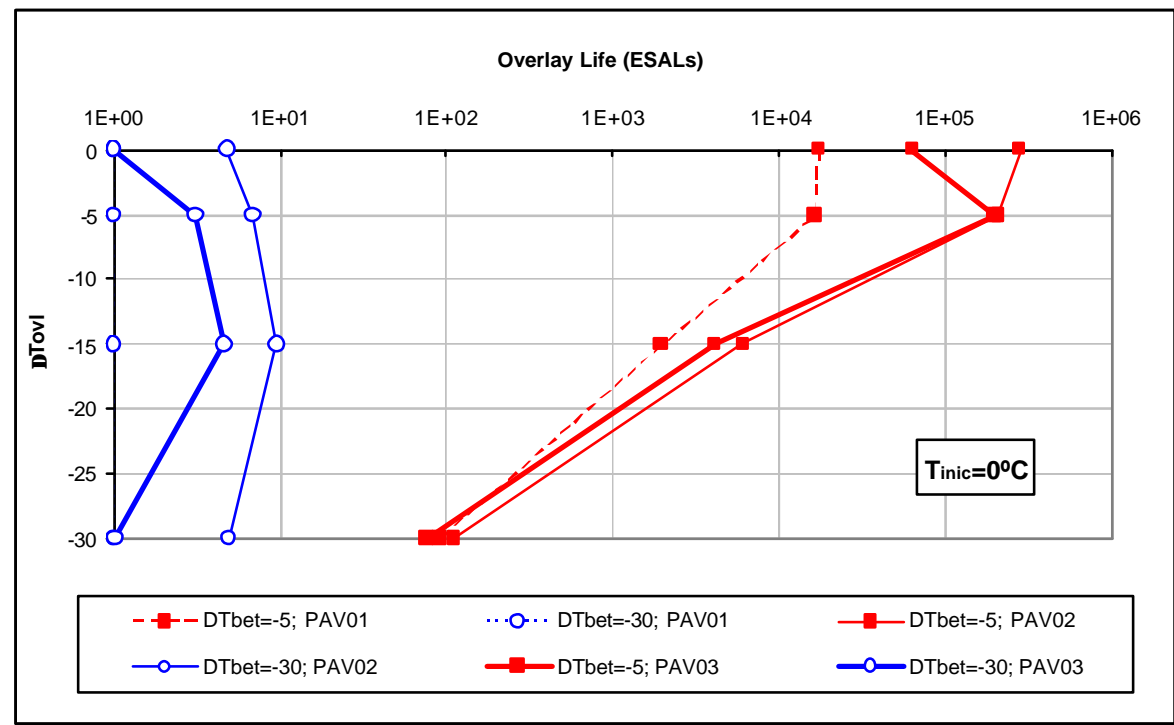

Figure 15. Overlay life of all pavement types, as function of $\Delta T$ Tovl, for initial temperature of $0^{\circ} \mathrm{C}$ and for $-5^{\circ} \mathrm{C}$ and $-30^{\circ} \mathrm{C}$ temperature variation

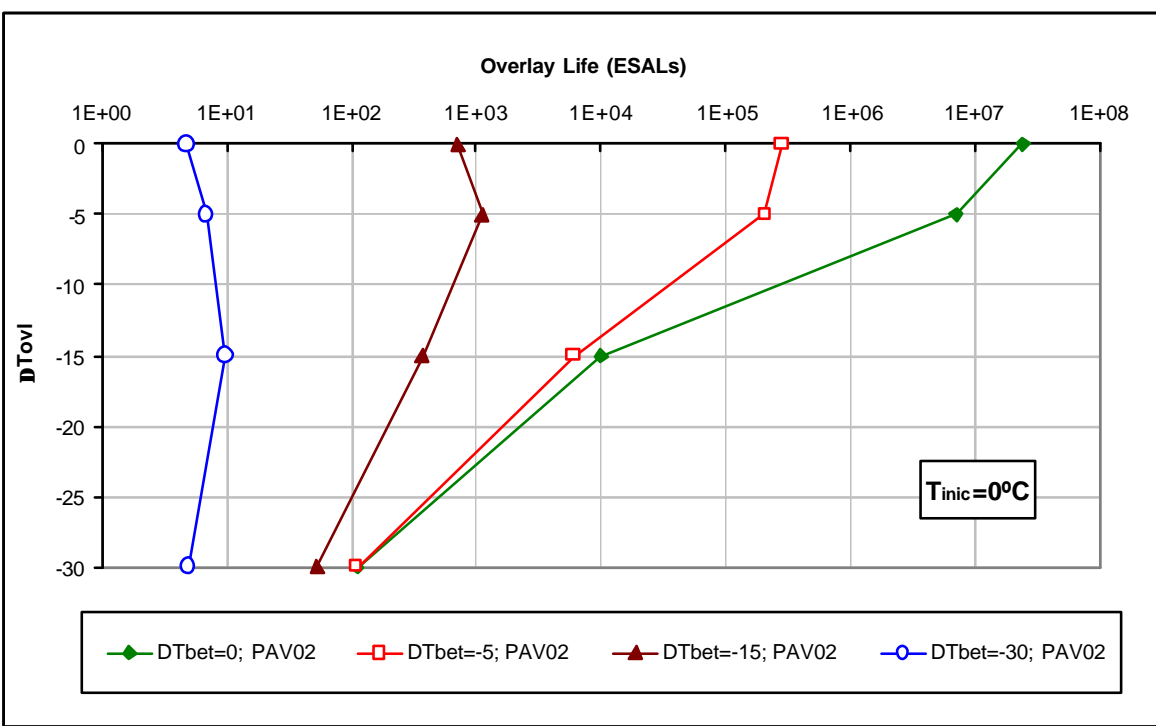

Figure 16. Overlay life of PAVO2 as function of $\triangle T$ Tovl, for initial temperature of $0^{\circ} \mathrm{C}$ and cracked layer temperature variation (Tbet) of $0^{\circ} \mathrm{C},-5^{\circ} \mathrm{C},-15^{\circ} \mathrm{C}$ and $-30^{\circ} \mathrm{C}$ 


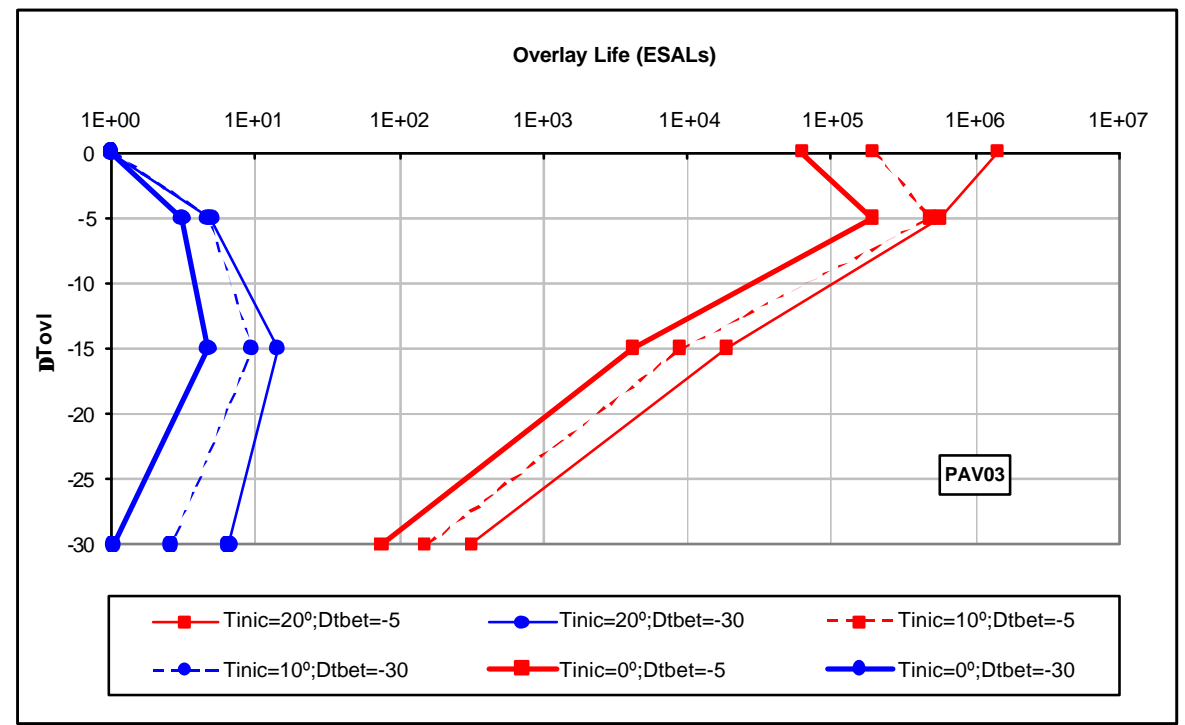

Figure 17. Overlay life as function of $\triangle T$ Tovl, for PAV03 for -5 and $-30^{\circ} \mathrm{C}$ temperature variation on cracked layer and initial temperature of $20^{\circ} \mathrm{C}, 10^{\circ} \mathrm{C}$ and $0^{\circ} \mathrm{C}$

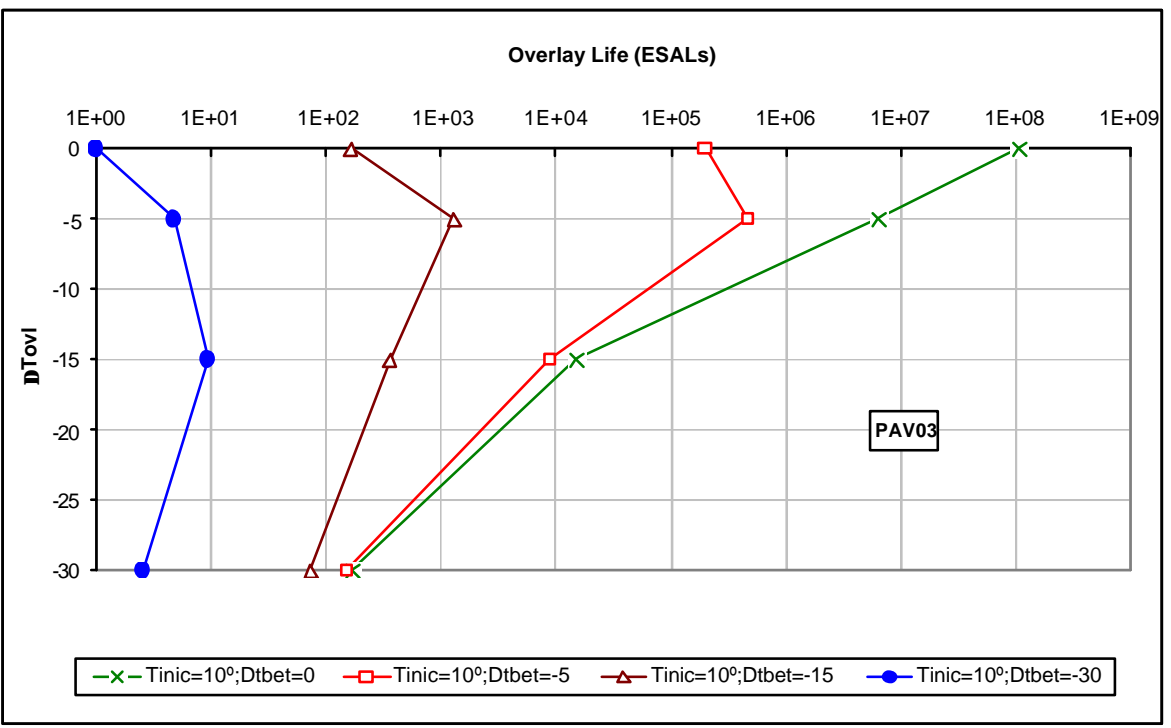

Figure 18. Overlay life as function of $\triangle T$ Tovl, for PAV03 and for initial temperature of $10^{\circ} \mathrm{C}$ 


\subsection{Influence of Uniform Temperature Variation in Bituminous Layers in the Overlay Life}

The FEM analysis was also carried out to calculate the state of stress and the overlay life when temperature variation was the same for all bituminous layers. This simulation corresponds to the usual situation in the current pavement design.

Thus, in Figure 19, the overlay life is plotted against the uniform temperature variation in all bituminous layers. This simulation was only made for an initial temperature of $20^{\circ} \mathrm{C}$ with temperature variations of $\left(-5^{\circ} \mathrm{C},-15^{\circ} \mathrm{C}\right.$ and $\left.-30^{\circ} \mathrm{C}\right)$. The traffic load was included in the calculation of the state of stress.

Identical results were obtained for the uniform temperature variation in all bituminous layers. The overlay life decreases when the temperature in the bituminous layer decreases. In this case, the fatigue life for low temperatures is reduced.

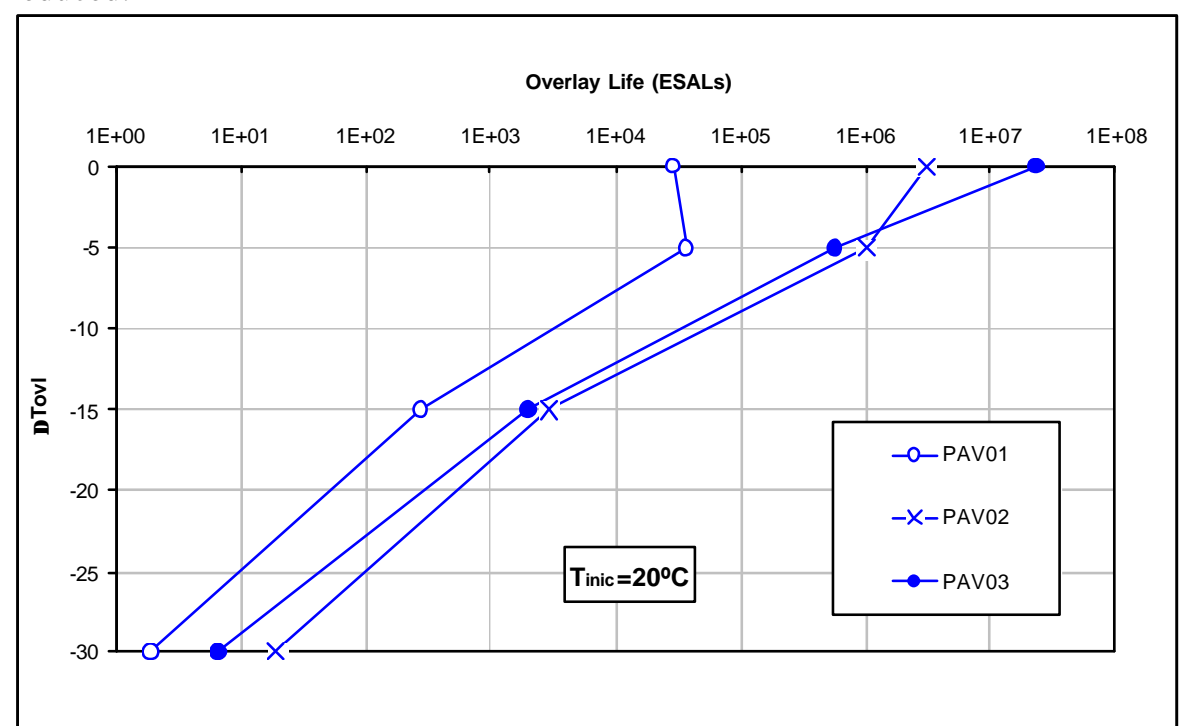

Figure 19. Overlay life as function of $\Delta$ Tovl, for traffic + temperature loading, for uniform temperature variation in both bituminous layers

\section{Evaluation of Asphalt Rubber Hot Mixes Overlays}

Finally, the overlay life was predicted by adopting an asphalt rubber hot mix in the overlay material, using the results presented in [SOU 2002]. In this study, fatigue tests were conducted in laboratory using asphalt rubber hot mixes with PG 64-16 asphalt cement interacted with $20 \%$ crumb rubber from California, generally referred as Arizona "Type A" AR Binder. For California AR binder, AR-4000 asphalt cement was mixed with California crumb rubber, natural rubber, and 
extender oil in a manner consistent with routine California work (generally called the "Type B" AR binder).

The binder content for the AR gap-graded mix (AR-HMA-GG) was $8 \%$, consistent with typical Arizona and California mix types and designs. The flexural fatigue tests conducted in displacement control mode of loading, produce the fatigue life law as function of the Von Mises strain:

$$
E S A L s=4.1245 E 19 *\left[\varepsilon_{V M}\left(1 \times 10^{-6}\right)\right]^{-4.9761}
$$

Where: ESALs = Equivalent standard axle loads;

$\varepsilon_{\mathrm{VM}}=$ Von Mises strain .

Using Equation [3], the overlay life was calculated for asphalt rubber mixes and compared to conventional mixes. Results presented in Figure 20 show that the asphalt rubber mixes present a considerable difference, in terms of fatigue life, when compared to conventional mixes. These differences are more significant for high temperature variations.

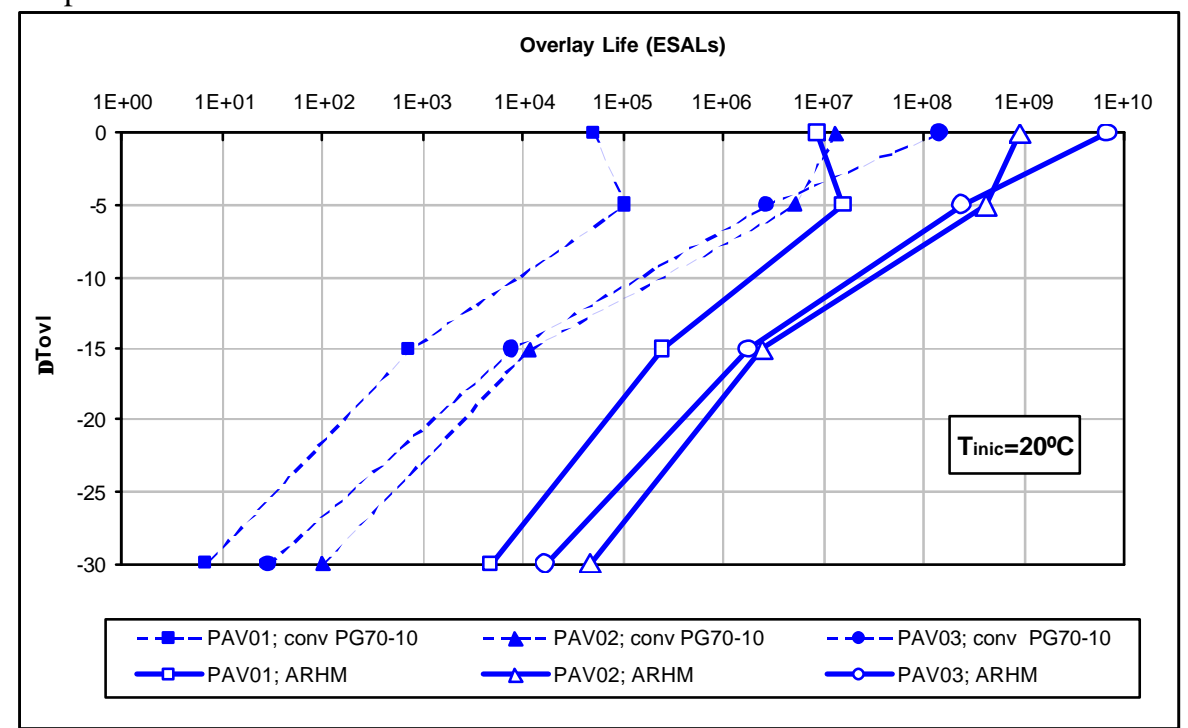

Figure 20. Comparison between overlay life for conventional and asphalt rubber mixes

\section{Conclusion}

This paper describes the influence of temperature variations in the pavement overlay life when the reflective cracking distress is taken into account. The applied thermal loading was defined in steady state and the material properties were considered with an elastic linear behavior in the finite-element modelation. The influence of pavement and load characteristics on state of stress and strain was 
evaluated by using the Von Mises strain deviatory concept and the prediction of the overlay life was based on the results of flexural fatigue tests, in a strain controlled mode of loading.

The analysis of this study proved that the finite-element method was an interesting tool to simulate the performance of asphalt concrete overlays under traffic and thermal loading conditions.

The rapid cooling rates that cause overall states of tension in the overlay are particularly important for estimating the overlay life. The temperature effect in the material properties has a positive impact on the overlay life. Furthermore, the effect of accumulated restrained thermal stresses as a result of cold temperature shrinkage, added to traffic loading, reduces the overlay life.

Consequently, the application of this study on asphalt rubber mixes and conventional mixes concluded that asphalt rubber mixes present more fatigue life at high temperature variations.

The effect of cold temperature shrinkage may have a significant influence in overlay life, which in turn, justifies special attention to overlay design procedures.

\section{References}

1. [SOU 2002] Sousa, Jorge B., Pais, Jorge C., Saim, Rachid, Way, George \&, Stubstad, Richard N 2001. Development of a Mechanistic-Empirical Based Overlay Design Method for Reflective Cracking, Journal of the Transportation Research Board, 2002.

2. [HAL 1989] Abd el Halim, A.O, 1989. A New Approach Toward Understanding the Problem of Reflective Cracking. Proceedings of the First International RILEM Conference on Reflective Cracking in Pavements.

3. [HAL 1990] Abd el Halim, A.O. \& O.J. Svec, 1990. Influence of Compaction Techniques on the Properties of Asphalt Pavements. Proceedings of the Canadian Technical Asphalt Association, Volume XXXV.

4. [SHA 1990] A. Shalaby, Abd el Halim A.O and O.J. Svec, 1990. Lowtemperature stresses and fracture analysis of asphalt overlays. Proceedings, Transportation Research Record 1539, pp 132-139.

5. [EPP 2000] Epps, Amy L., 1997. Thermal behavior of crumb-rubber modified asphalt concrete mixtures. Dissertation series UCB-ITS-DS-97-2. Institute of Transportation Studies, University of California at Berkeley. ISBN 01924109

6. [BON, 2000] de Bondt Arian. Effect of Reinforcements Properties. Proceedings PRO11. $4^{\text {h }}$ International RILEM Conference on Reflective Cracking in Pavements - Research in Practice. Edited by A. O. Abd El Halim, D. A. Taylor and El H. H. Mohamed. RILEM. Ottawa, Ontario, Canada. March 2000 